\title{
CESPUC
}

\section{UMA RELAÇÃO ENTRE A CONCEPÇÃO ARTÍSTICA DA OBRA POÉTICA DE EDGAR ALLAN POE E A TEORIA DE POLISSISTEMAS}

Pedro Alves de Oliveira Brito*

\begin{abstract}
Resumo
$\mathrm{O}$ ato tradutório, envolto em extensa gama de preconceitos, continua sendo visto como prática invisível, inescapavelmente presente, mas raramente reconhecida. Sabe-se, no entanto, que, através da tradução, o tradutor não está simplesmente interpretando um texto na língua original, em seguida produzindo um texto correspondente na língua alvo. Ao nos aprofundarmos no tema, percebe-se que o conceito de tradução poética se vê obrigado a distanciar-se de outros que, de forma semelhante, estejam ligados à tradução literária. Com base nessas considerações, o trabalho apresenta, utilizando como pilar a teoria de polissistemas de Itamar EvenZohar, a concepção artística da poesia de Edgar Allan Poe, bem como os elementos teórico e literário presentes no potencial tradutório de sua obra.
\end{abstract}

Palavras-chave: Literatura comparada. Edgar Allan Poe. Teoria de polissistemas.

\section{A RELATION BETWEEN THE ARTISTIC CONCEPTION OF EDGAR ALLAN POE'S POETIC WORKS AND THE POLYSYSTEM THEORY}

Recebido em: 21/02/2017

Aceito em: 04/05/2017

* Universidade Federal de Ouro Preto (UFOP). Mestre em Letras (Estudos da Linguagem). 


\section{Pedro flves de Oliveira Britoe}

10 SEMESTRE DE 2017 - N. 30

\section{Introdução}

Segundo Lawrence Venuti (1992, p. 1), o "eclipse do trabalho do tradutor, do próprio ato de traduzir e sua mediação decisiva da escrita estrangeira, é palco de múltiplas determinações e efeitos - linguísticos, culturais, institucionais, políticos". ${ }^{1}$ Ignora-se, destarte, a relação entre autoria e tradução, tratada, por exemplo, em 2008 por Solange Mittmann, que discute a figura do tradutor sob uma ótica autoral, ou, ainda, o lugar que o tradutor ocupa na relação sobre a produção, podendo se tornar quiçá coautor do texto de chegada.

Entretanto se busca observar uma "cláusula de fidelidade" (CHARAUDEAU, 2011), que garante uma relação de equivalência semântica, pragmática e sociocultural entre o texto traduzido e seu original. Segundo Mittmann (2008, p. 1), "o processo tradutório revela que as bordas dos textos são ilusórias, pois as fendas se mostram a cada trecho a ser traduzido, explicado, ou mesmo silenciado".

Faz-se pertinente uma menção a Robert Frost (1995, p. 865), a quem é atribuída a seguinte reflexão: "A poesia é o que se perde na tradução". ${ }^{2}$ Explica-se: o poeta, ao fazer uso de relações sintagmáticas e paradigmáticas, torna o poema, a princípio, construção linguística diferenciada, posto que a linguagem poética, grosso modo, se reveste de uma forma que afronta a objetividade da realidade pragmática. Buscando atingir um elevado grau de significação, fazse uso de relações morfológicas, fonológicas, sintáticas e semânticas, a partir das quais o texto, transformando-se em sua própria referência, projeta o leitor em direção ao universo textual. Ademais, a tradução poética remete à formalidade estrutural da qual ela é impreterivelmente refém, já que o autor se vale exatamente dessa para costurar sua obra, concedendo-lhe a plenitude que lhe é devida.

Estes fatores acabam conduzindo os teóricos a um denominador comum: a impossibilidade ou a inferioridade da tradução. Paul Valéry (s/d, apud ARROJO, 1986), por exemplo, classifica a qualidade do texto poético como sendo diretamente proporcional à sua traduzibilidade: "quanto mais resistente for o texto "aparentemente" poético ao ataque de qualquer transformação formal, maior será o seu grau de poesia”.

Roman Jakobson, em seu livro Aspectos linguísticos da tradução, publicado pela primeira vez em 1959, chegou a declarar que "a poesia, por definição, [é, em seu sentido primário,] intraduzível”. De acordo com o linguista, só é possível praticar uma espécie de transposição criativa, se esta traduz em uma de três possibilidades: a transposição de uma forma poética para outra, dentro de uma língua; ou a transposição de uma língua para outra; ou a transposição semiótica de um sistema de signos para outro.

Já Bassnett e Lefevere (1990) pregam uma dicotomia de valores concernentes ao tema. Se, por um lado, traduzir é reescrever, e reescrever é manipular - refletindo uma transferência carregada de novas ideologias -, por outro, essa carga ideológica pode funcionar exatamente como "propulsor evolutivo" da literatura do país de destino e até mesmo de sua sociedade,

1 Tradução própria de "This eclipse of the translator's labor, of the very act of translation and its decisive mediation of foreign writing, is the site of multiple determinations and effects - linguistic, cultural, institutional, political” (VENUTI,1992, p. 1).

2 Tradução livre de "Poetry is what gets lost in translation". 


\section{CESPUC \\ 1 O SEMESTRE DE $2017-$ N. 30}

tendo lugar a "introdução da visão do texto literário no seu papel de transformação social" (VIEIRA, 1992, p.100). Por este viés, há de se destacar, segundo Charles Norton, que o que se processa na tradução é:

A transfusão poética do espírito poético de uma língua para outra, e a representação de ideias e imagens do original em uma forma não totalmente diversa da sua própria, mas perfeitamente adaptada a novas condições de tempo, lugar, costumes e hábitos de pensamento nos quais eles reaparecem. (NORTON apud CARVALHAL, 2003, p. 228).

Even-Zohar, em sua coleção de ensaios intitulada Papers in historical poetics (1978), propõe que se analisem as literaturas original e traduzida como um agregado polissistêmico. Sua abordagem se fundamenta na hipótese de que seria mais conveniente agrupar todos os gêneros de textos literários e semiliterários em um conjunto heterogêneo de sistemas. Ele observa que o papel de uma tradução em um dado sistema literário está inerentemente conectado à evolução histórica deste sistema, que está necessariamente em constante processo evolutivo, e que esse processo é, inescapavelmente, de natureza sistêmica.

\section{O legado}

Edgar Allan Poe é tido por muitos como um dos maiores nomes da literatura de seu país, tendo sido inclusive traduzido por expoentes do cânone literário universal, como Fernando Pessoa e Mallarmé - o que contribuiu para a formação de sua fortuna crítica. Por outro lado, sua aceitação como grande poeta está longe de ser unânime - haja vista as palavras de Thomas Sterns Eliot, que pontua:

Se examinarmos seu trabalho minuciosamente, parece que encontramos nada além de uma escrita desleixada, um pensamento pueril desamparado por leitura ampla ou conhecimento profundo, experiências desordenadas em vários tipos de escrita, principalmente sob pressão financeira, sem nenhuma atenção nos detalhes. (ELIOT, 1965, p. 27). ${ }^{3}$

Não obstante, o próprio crítico reconhece, no mesmo ensaio, a importância de Poe, tanto quanto possa ser relacionada às ponderações de Baudelaire, que qualifica a literatura do poeta como "extra ou super-humana", colocando-o em nível distinto daquele de sua pátria. Além, de acordo com Cortázar, Poe entendia a poesia segundo seus próprios poemas e a partir deles, e todas as reflexões seguintes se relacionam à matéria poética elementar. "Poe era inteligente demais para não compreendê-lo, embora sua inteligência tenha forçado com frequência o limite natural da sua poesia, já seja no próprio poema, já nos textos críticos que analisam a criação poética" (CORTÁZAR, 2006, p. 114).

Precursor do gênero detetivesco moderno, ele também é considerado parte do Movimento Romântico Americano - ainda que por vezes se desvencilhasse de tal amarra. A despeito disso, Morton Zabel coloca que:

3 Tradução própria de "If we examine his work in detail, we seem to find in it nothing but slipshod writing, puerile thinking unsupported by wide reading or profound scholarship, haphazard experiments in various types of writing, chiefly under pressure of financial need, without perfection in any detail". (ELIOT, 1965, p. 27). 
Suas lúgubres histórias e poemas esconjurados são parte da época e do lugar que o produziram; suas tonalidades e inflexões ecoam numa distinta e autêntica corrente da literatura ulterior de seu país. Fazem-nos lembrar que os inícios de uma literatura definidamente nacional, nos Estados Unidos, durante a primeira metade do século Dezenove, coincidiram com o período da literatura moderna que denominamos Movimento Romântico. (ZABEL, 1947, p. 87).

Dessa maneira, entende-se que Poe trouxe à sua poética diversas características dessa escola, de modo que a ela podem ser atribuídos, ainda que de forma restrita, traços que remetam diretamente ao Romantismo, como a beleza poética e o distanciamento da realidade - muito embora seus trabalhos mais conhecidos se enquadrem no gênero gótico, do qual se ramifica o Romantismo Sombrio. ${ }^{4}$

Essa variação do Romantismo garantiu à poesia atributos macabros, donde se verificam temas recorrentes, tais como a morte, os efeitos da decomposição, preocupações com enterros prematuros, reanimação dos mortos e luto. Segundo Zabel (1947, p. 82), em Poe encontra-se "um mundo de estranhezas e terror, de espectros mórbidos e luzes lúgubres, de palácios malassombrados, terrificantes pesadelos, paisagens febris e sonhos aniquiladores". Logo, Allan Poe baseou sua obra poética no sobrenatural - em que a morte e o luto são lugares comuns. Por outro lado, ele se valia de ironias e extravagâncias para o alcance de efeito cômico, ou talvez, em meio à atmosfera e tons relacionados à melancolia, dir-se-ia tragicômico.

O romantismo, por sua vez, enfatizava "intuição", "imaginação" (distanciamento da realidade) e "sentimento" de tal modo que levou alguns dos escritores românticos a serem julgados como adeptos do irracionalismo. Esse fato contribuiu para que Poe publicasse um ensaio sob o título de The Philosophy of Composition, através do qual trata de esclarecer os métodos os quais utilizou para compor "The Raven". Cortázar, a esse respeito, pondera:

A poesia é uma urgência, cuja satisfação é alcançada, cumprindo-se certas formalidades, adotando-se certos procedimentos. Mas a noção de poema a frio, que parecia nascer do texto da Filosofia da composição, se vê sensivelmente diminuída. À luz desta admissão de um ímpeto poético que tem toda a violência daquele que os românticos reconheciam, $\mathrm{O}$ corvo deve ser reconsiderado. Não há dúvida de que neste poema há muito de excessivamente fabricado, visando a obter um profundo efeito geral por meio da sábia gradação de efeitos parciais, de preparação psicológica, de encantamento musical. Neste sentido, o relato que Poe nos faz de como o escreveu parece corroborado pelos resultados. Sabe-se, contudo, que a verdade é outra: O corvo não nasceu de um plano infalivelmente preconcebido, mas, sim, de uma série de estados sucessivos [...], onde a tarefa de pôr e tirar palavras, pesar cuidadosamente cada ritmo [...], alcança uma perfeição menos arquitetônica do que mecânica. (CORTÁZAR, 2006, p. 116).

A partir dessa reflexão, cabe dizer que a crítica de Eliot traz à tona uma questão: que motivos levaram a poesia de Allan Poe a atrair a atenção de grandes nomes da literatura, como Baudelaire e Mallarmé? Valendo-se novamente das palavras de Eliot, "[sua obra] teve uma importante influência nos autores, e em estilos de escrita onde tal influência seria dificilmente esperada" (ELIOT, 1965, p. 27). ${ }^{5}$

4 Tradução livre de "Dark Romanticism".

5 Tradução própria de "[his work has] had an important influence upon authors, and in types of writing where such influence would hardly be expected" (ELIOT, 1965, p. 27)". 


\section{CESPUC

Ademais, Cortázar (2006, p. 117) considera que tais conjecturas "abrangem apenas a metade explícita da poética de Poe, deixando velado o setor que ele mesmo dissimulava ou dificilmente consentia em manifestar em textos colaterais aos seus ensaios doutrinários". O próprio Poe já lembra em seu ensaio "The poetic principle" que "um poema só merece este título enquanto emociona, elevando a alma. O valor do poema está na razão dessa emoção crescente" (POE, [1846]/1994, p. 1.543) ${ }^{6}$. Ora, se é combinável este fator, que faz da poesia uma poesia, à rigidez matemática encontrada, por exemplo, em "The Raven", como esta poderia ser equacionada de forma que seu resultado, ao ser traduzida, não fosse alterado? Como, por exemplo, um autor realista brasileiro - como é o caso de Machado -, não poderia imprimir sua própria marca na obra original, que tem temática típica do romantismo, transformando-a, mesmo que de forma sutil?

Partindo de tal pressuposto, à luz do que oferece a teoria de polissistemas, pretende-se, através deste trabalho, abordar aspectos concernentes ao tema, bem como tentar colocá-los à prova, analisando traduções da poesia de Edgar Allan Poe, quais sejam: "Alone" (1829), “The Raven" (1845) e "Annabel Lee" (1849). Dentre os tradutores destacam-se dois nomes que sustentam o cânone literário de seus respectivos países de origem: Machado de Assis e Fernando Pessoa. Fazem parte da relação, além, Milton Amado, que traduziu - em parceria com Oscar Mendes - cada uma das obras citadas, e Augusto de Campos, que deu sua contribuição ao verter "Alone" para o português.

Machado de Assis, tido por muitos como o maior nome da literatura brasileira, pode ser considerado o primeiro grande escritor a trazer a obra de Poe à literatura de língua portuguesa, muito embora se possa inferir que sua tradução traz maior semelhança à de Charles Baudelaire, que data de 1853, do que à original. Em 1883, ao se ocupar da tradução de "The Raven", "O Bruxo do Cosme Velho" faz valer, trinta anos depois de Baudelaire tê-lo feito, sua representação parnasiana da poética poeana, enquanto busca adaptar o poema a um novo contexto, com o intuito de formar uma identidade literária nacional. Em oposição à postura servil do tradutor ao original, ainda preconizada por muitos em sua época, Machado recria, traz à tona novos elementos, incorporando em sua tradução as influências de sua formação literária.

Fernando Pessoa, em sua instância, traduziu “The Raven” em 1924 - mesmo ano em que fundou a revista Athena -, imprimindo em seu texto uma carga poética muito próxima à carga poética dos refrões de Poe. A partir de visível conhecimento de causa, Pessoa, em um excerto intitulado "The art of translating poetry", mostrou além:

Um poema é uma impressão intelectualizada, ou uma ideia transformada em emoção, comunicada a outros por meios de um ritmo. [...] A tradução de um poema deveria, portanto, [ajustar-se] absolutamente (1) à ideia ou emoção que constitui o poema; (2) ao ritmo verbal através do qual a ideia ou emoção é expressada; ela deveria ajustar-se relativamente ao ritmo visual ou interior, mantendo as próprias imagens quando possível, mas sempre se atendo ao tipo de imagem. Foi a partir desses critérios que eu baseei minhas traduções para o Português de Annabel Lee e Ulalume, escritos por Poe, os quais eu traduzi,

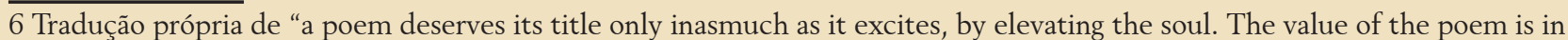
the ratio of this elevating excitement" (POE, The Philosophy of Composition, 1846.In: BAYM (Org.), [1846] 1994, p. 1.543). 


\section{CESPUC \\ 1 O SEMESTRE DE $2017-$ N. 30}

não devido à seu grande valor intrínseco, mas porque eram um permanente desafio aos tradutores. ${ }^{7}$ (PESSOA, 1988. p. 54).

Conclui-se, dessa forma, a apresentação dos tradutores da obra poética de Allan Poe, ao passo que se faz pertinente discorrer sobre outro ponto de igual relevância ao estudo: a concepção artística do poeta.

\section{Concepção artística}

Ao percorrer os caminhos sombrios de Nevermore, Allan Poe se apegou a um processo metodológico preciso, impregnando seu poema "The Raven" de simetria lógica do início ao fim. A rigidez matemática aplicada pelo escritor pode ser percebida em toda a extensão da obra, principalmente se atentarmos à sua estrutura poética. Defendendo a prática da arte de forma deliberada - em oposição a efusões incontroladas, Poe tratou a composição do poema como a um problema aritmético; muito embora se deva sublinhar o fato de não se tratar de uma matemática quantitativista, "medida por números equivalentes, e, sim, por uma disciplina guiada pela intuição da similaridade, pela simetria ou consistência”. (ARAÚJO, 2002, p. 92).

O autor, discorrendo sobre a criação do poema, trata exatamente de aspectos como esse em seu ensaio The Philosophy of Composition (1846), escrito nos terrenos da estética, da crítica e da teoria literária. Podendo ser pertinentemente adaptado como A Teoria da Escrita, Allan Poe disseca não somente a obra, mas todo o processo através do qual ela foi criada.

Nas palavras de Cortázar,

O poeta entende a poesia segundo seus próprios poemas, olha-a a partir deles e com eles, e as reflexões posteriores estão forçosamente subordinadas à matéria poética elementar, a que toma forma no verso. Poe era inteligente demais para não compreendê-lo, embora sua inteligência tenha forçado com frequência o limite natural da sua poesia, já seja no próprio poema (fazendo de $\mathrm{O}$ corvo uma espécie de sutilíssimo relógio de repetição, de máquina de beleza, segundo ele entendia a coisa), já nos textos críticos que analisam a criação poética. Mas por mais que tergiversasse a verdade, alterando a interpretação da sua própria poesia e da alheia com "princípios" extraídos dedutivamente, o conjunto geral desses princípios coincide, como vamos ver, com o tom autêntico dos seus poemas. Por mais que às vezes nade contra a corrente, Poe não pode sair do rio da sua própria poesia. Sua poética é como que uma tentativa de negar o tronco da árvore e afirmar, ao mesmo tempo, seus ramos e sua folhagem; de negar a irrupção veemente da substância poética, mas aceitar suas modalidades secundárias. (CORTÁZAR, 2006, p. 114).

Em se tratando do ensaio propriamente dito, os primeiros sete parágrafos são dedicados a criticar sobremaneira a repugnância aludida à prática de relembrar e divulgar os passos progressivos de qualquer composição, bem como a criação em si, dizendo que "há um erro

7 Tradução própria de "A poem is an intellectualized impression, or an idea made emotion, communicated to others by means of a rhythm. [...] The translation of a poem should therefore [conform] absolutely (1) to the idea or emotion that constitutes the poem; (2) to the verbal rhythm in which that idea or emotion is expressed; it should conform relatively to the inner or visual rhythm, keeping the images themselves when it can, but keeping always to the type of image. It was on this criterion that I based my translations into Portuguese of Poe's Annabel Lee and Ulalume, which I translated, not because of their great intrinsic worth, but because they were a standing challenge to translators" (PESSOA, 1988. p. 54). 
radical, [acha,] na maneira habitual de construir uma ficção" (POE, 1846). De acordo com Poe, uma composição poética deveria começar pela consideração de um "efeito" e, a partir dele, desenvolver o contorno da obra - garantindo a ela uma "unidade de efeito".

De todo modo, ao iniciar a análise de "The Raven", o autor atesta, de forma veemente, que "nenhum ponto de sua composição se refere ao acaso, ou à intuição, que o trabalho caminhou, passo a passo, até completar-se, com a precisão e a sequência rígida de um problema matemático" (POE, 1846) - segundo Eco, que também se debruça sobre Poe, "posição realmente provocadora, como sempre se observou, pois introduzia um elemento de cálculo formal em um ambiente dominado pelo conceito romântico da poesia como produto de inspiração súbita" (ECO, 2007, p. 336). Dito isso, Poe faz considerações acerca da criação da obra, apoiando-a em três pilares: "extensão", "província" e "tom".

No que tange ao parâmetro "extensão", ele dita que, se determinada obra literária é muito longa para ser lida em uma sentada, o autor deve se contentar em dispensar o conceito de unidade de impressão. Portanto, se duas sentadas são necessárias, os acontecimentos do mundo vão interferir na leitura, sendo a totalidade da obra destruída de uma vez por todas. Além disso uma poesia longa é, na verdade, nada mais do que uma sucessão de pequenas poesias, ou pequenos efeitos poéticos. Poe calcula - fazendo nova relação matemática - que certo grau de duração é requisito absoluto para a produção de qualquer "efeito". Visando a tais pontos, o poeta considera apropriado que a um poema sejam designadas não mais que 108 linhas.

Parte-se, então, para o segundo parâmetro: "Beleza é a única província legítima do poema" (POE, 1846). De acordo com Allan Poe, essa beleza não é exatamente uma qualidade, como se supõe, mas um "efeito". Refere-se, em suma, àquela intensa e pura elevação da alma, e não da inteligência, do coração. Deve se deixar claro que era de suma importância para o autor tornar "The Raven" universalmente apreciável - tanto para o público quanto para os críticos. Tendo o segundo pilar definido, faz-se conexão direta com o terceiro - o "tom". Todas as experiências mostraram que o tom de mais alta manifestação é o da tristeza: "A beleza, de qualquer espécie, em seu desenvolvimento supremo, invariavelmente provoca na alma sensitiva as lágrimas" (POE, 1846), de modo que a Melancolia pode ser vista como o mais legítimo de todos os tons poéticos. Quanto à natureza dessa Melancolia, no caso, ele decide por aquela que seria invariavelmente absorvida por todos: a morte de uma mulher. Acreditando ser inquestionavelmente o uso mais poético do sentimento, o autor argumenta que esse fator se alia diretamente ao conceito de Beleza. Ademais, a essa altura já se percebe a preeminência romântica em sua obra, quer-se dizer, torna-se nítida a presença na obra dos atributos relacionados à escola em questão, como visto na seção anterior.

Delimitados então "extensão", "província” e "tom”, Poe passa a pensar nos efeitos artísticos ou, mais propriamente, recursos poéticos. $\mathrm{O}$ escritor não falhou em perceber imediatamente que, naquele ponto, nenhum recurso havia sido tão universalmente empregado quanto o refrão. E essa universalidade foi suficiente para assegurar seu valor intrínseco, e o poupou da necessidade de submeter esse recurso a uma análise. Poe, entretanto, fica preso a um dilema, como pode ser observado em seu outro ensaio "The poetic principle": 


\section{CESPUC \\ 1 O SEMESTRE DE $2017-$ N. 30}

Considerei-o, contudo, em relação à sua suscetibilidade de aperfeiçoamento e vi logo que ainda se achava num estado primitivo. Como é comumente usado, o refrão poético, ou estribilho, não só se limita ao verso lírico, mas depende, para impressionar, da força da monotonia, tanto no som, como na ideia. (POE apud MENDES; AMADO, [1850]/1999, p. 106).

O prazer da leitura, então, é extraído do sentido de identidade - de repetição. Desse modo, ele passa a especular em torno da natureza do refrão.

Já que a aplicação deste deve ser variada repetidamente, fica claro que ele deve ser breve, principalmente devido à dificuldade de inseri-lo em variações de sentenças no poema. Concluise, então, que o melhor refrão possível deva ser reduzido a uma simples palavra - definindo a última palavra de cada estrofe para executar tal serviço. Dessa forma, as considerações feitas levam Poe a deduzir que a palavra deva ser suscetível de ênfase, encontrando o /o/ prolongado como a vogal mais sonora, em conjunto com o /r/, a consoante mais aproveitável.

Ficando, então, determinado o som, torna-se necessário selecionar uma palavra que personifique esse som, e que ao mesmo tempo mantenha constantemente a melancolia que Poe determina como tom do poema. Em tal busca é, de acordo com ele, absolutamente impossível ignorar a palavra "Nevermore".

De todo modo - voltando ao início -, é pertinente afirmar que o ponto mais importante a ser considerado em The philosophy of composition é o fato de que o poema é escrito de trás para frente. O efeito é determinado de antemão e a partir dele toda a trama é construída, em sentido oposto, tendo aquele único efeito em vista. Segundo Poe,

Nada é mais claro do que deverem todas as intrigas, dignas desse nome, ser elaboradas em relação ao epílogo, antes que se tente qualquer coisa com a pena. Só tendo o epílogo constantemente em vista, podemos dar a um enredo seu aspecto indispensável de consequência, ou causalidade, fazendo com que os incidentes e, especialmente, o tom da obra tendam para o desenvolvimento de sua intenção. (POE apud MENDES; AMADO, [1846]/1999, p.101).

Outrossim, Allan Poe começou escrevendo a estrofe que leva o interrogatório do narrador ao corvo até o clímax - a décima sexta estrofe -, e observa, cautelosamente, para que nenhuma outra pudesse ultrapassá-la em seu efeito rítmico. Em palavras do próprio autor, "Aí, então, pode-se dizer que o poema teve seu começo pelo fim, por que devem começar todas as obras de arte" (POE, 1846). Dessa maneira, ele elabora o contorno do poema em torno da referida estrofe, usando "Nevermore" em vários sentidos, com o intuito de não tornar monótona a repetição do refrão.

A escolha de Poe traz também outros benefícios, como ele mesmo constatou:

[...] estabelecendo o ponto culminante, melhor poderia variar e graduar, no que se refere à seriedade e importância, as perguntas precedentes do amante e, em segundo lugar, porque poderia definitivamente assentar o ritmo, o metro, a extensão e o arranjo geral da estância, assim como graduar as estâncias que a deviam preceder. (POE, 1846) 


\section{CESPUC \\ 1 O SEMESTRE DE $2017-$ N. 30}

Allan Poe, ademais, critica o didaticismo e a alegoria, muito embora ele acreditasse que o "sentido", na literatura, deve se encontrar logo abaixo da superfície. Obras que apresentem sentidos óbvios, de acordo com o autor, cessam de ser arte. Ele acredita que um trabalho de qualidade deve se concentrar em um único e específico "efeito". Para esse fim, ele diz que o escritor deve calcular cuidadosamente cada sentimento e ideia empregados. Reflexões como essas podem ser encontradas em seu outro ensaio, que foi publicado sob o nome de The poetic principle (1850).

De acordo com Baudelaire:

Poe escolheu um tema tão vasto como elevado: O Princípio da Poesia, e desenvolveu-o com aquela lucidez que é um dos seus privilégios. Pensava, como verdadeiro poeta que era, que o objetivo da poesia é da mesma natureza do seu princípio, e que ela não deve ter em vista outra coisa senão ela mesma. (BAUDELAIRE, 2006, p. 80).

Voltando ao conceito de "extensão", Poe defende, além, que não existem poemas longos; o que ocorre é apenas uma sucessão de poemas curtos: "sustento que a frase 'um poema longo' é simplesmente categórica contradição nos termos" (POE, 1850). Ele ainda cita o exemplo da Ilíada, de Homero, que é formada por uma "série de líricas".

Em Novas notas sobre Edgar Poe, Baudelaire (1857), para criticar de forma veemente a Estética clássica, trata dos dois ensaios de Allan Poe que mais repercutiram no meio literário. Entre outras questões, o poeta atesta que, para Poe, a Imaginação é a rainha das faculdades e que essa Imaginação "é uma faculdade quase divina que antes de mais [nada] apreende, para além dos métodos filosóficos, as relações íntimas e secretas entre as coisas, as correspondências e as analogias" (BAUDELAIRE, 2006, p. 104). Desse modo, à luz de tais conceitos, Edgar Allan Poe escreveu sua obra prima, cuidando meticulosamente para que atendesse a todos os seus propósitos de poeta e crítico literário.

\section{Considerações finais}

Um texto é a interseção de todos as experiências vivenciadas pelo seu artífice: ao se escrever, o que se reproduz - direta ou indiretamente - dá conta do histórico cognitivo intertextual de quem escreve. Ao se aplicar essa reflexão ao processo de tradução poética, entende-se que o metatexto corresponde à transferência e interpretação, posto que, evidentemente, cada experiência e indivíduo são únicos. De acordo com Tânia Carvalhal (2003, p. 246), por exemplo, "fica claro então que uma tradução pode alterar o texto original sob influência do contexto da literatura de chegada".

Além, a literatura abrange distintas combinações de tempo e espaço - tudo aquilo que pode ser depreendido do sentido de cultura - que variam tanto para o poeta quanto para o leitor. A diferença, segundo Miner (1996, p. 34), pode ser irrelevante, como quando Pound lê o trabalho de Eliot - onde há maior aproximação tanto em tempo quanto em espaço -, ou pode ser grande, como quando, hoje, alguém que tenha o inglês como língua-mãe põe-se a ler os épicos sânscritos. Ademais, assim como a tradução, o texto fonte tem uma origem específica 
- de acordo com Venuti (2002), estando susceptível ao contexto histórico, social e político do autor, bem como à composição de seu repertório de leituras. Destarte, seria leviano determinar que certa obra possibilite apenas uma tradução, tal qual uma fotografia: cada versão trará sua própria bagagem literária, tal que todas poderão ser identificadas pela gama de atribuições que lhes é peculiar.

Assim, leva-se a tradução a outro nível, onde a fotografia dará lugar a uma tela em branco. O tradutor - aqui, no papel de pintor - emprestará sua própria visão à obra original, criando o novo. Desse modo, percebe-se que a tradução enriquece o texto fonte, longe de desvirtuar-se da intenção do autor - além, cria-se uma nova intenção. Deduz-se, então, que, segundo Haroldo de Campos (1967, p. 24), "[...] a tradução de textos criativos será sempre recriação, ou criação paralela, autônoma porém recíproca. [...] Está-se pois no avesso da chamada tradução literal”. Confirmando essa proposição, Walter Benjamin argumenta, em seu ensaio intitulado The task of the translator (1923), que, antes de se traduzir uma poesia, deve-se encontrar a intenção do poeta - o que pode ser observado no conceito de "unidade de efeito" proposto por Allan Poe -, de forma que um eco do original possa ser despertado na tradução. Portanto, o tradutor não se deve deixar afastar desse escopo: se o faz, torna inexistente o elo entre conteúdo e língua que, no original, constituem a unidade poética. ${ }^{8}$ (BENJAMIN, 1997, p. 159).

Não obstante, retomam-se as considerações de Venuti (2002, p. 115), para quem "a tradução possui uma autonomia relativa em relação ao texto estrangeiro, é um ato de criação da forma e, portanto, existe como um objeto independente do trabalho subjacente no qual está baseado”. Por este viés, à luz do que é oferecido por Gutt, a tradução passa a ter autonomia em relação ao texto de partida e cumpre uma função específica no sistema literário de chegada, deixando de ser produto derivacional para se tornar produto autoral. De acordo com ele, "qualquer que seja a decisão do tradutor, ela será baseada no que ele acredita ser relevante ao seu público”. ${ }^{9}$ (VENUTI, 2000. p. 386).

Ao se observarem estas reflexões sob o prisma da teoria de polissistemas, a análise é transportada a um novo estrato. De acordo com Even-Zohar:

Em primeira instância, uma literatura se desenvolve dentro de sua esfera. Às vezes um sistema ou indivíduo extrínsecos a ela pode ser de alguma importância para seu desenvolvimento, mas não quando se trata de sua capacidade de existir durante um longo período. Este tem sido o caso, por exemplo, das literaturas francesa e inglesa, há quase duzentos anos. Nenhuma delas se isolou do restante do mundo, e cada uma se desenvolveu usando uma variedade de fontes estrangeiras..$^{10}$ (EVEN-ZOHAR, 1997, p. 56).

8 Interpretação livre de "The translator's task consists in this: to find the intention toward the language into which the work is to be translated, on the basis of which an echo of the original can be awakened in it" (BENJAMIN, 1997, p. 159).

9 Tradução própria de "whatever decision the translator reaches is based on his intuitions or beliefs about what is relevant to his audience" (GUTT, Translation as interlingual interpretive use, 1991. In: VENUTI, 2000. p. 386).

10 Tradução própria de "In the first instance, a literature develops within its own spheres. Sometimes an outside system or individual may be of some importance for it, but never when it comes to its very ability to exist over a longer period of time. Such has been the case, e.g., of both French and English literatures for almost two hundred years. Neither of them has existed in isolation from the rest of the world, each having further developed its repertoire by using a variety of outside sources" (EVEN-ZOHAR, 1997, p. 56). 


\title{
CESPUC \\ 1 O SEMESTRE DE $2017-$ N. 30
}

Isso não quer dizer, contudo, que determinada obra, em versão original, seja mais eficaz ao integrar um sistema literário - o que se dá é exatamente o oposto: de acordo com Carvalhal (2003, p. 230), "mesmo que vários leitores possam ler uma obra no original, o texto não integra o sistema literário enquanto não for traduzido, enquanto uma forma apropriada ou uma dicção própria não for alcançada na "tradição" que passa a integrar" - visão corroborada pela teoria de Even-Zohar, que classifica a posição de uma literatura traduzida dentro de um sistema literário como central, e que ela molda ativamente o centro do polissistema. Com base nessas questões, o teórico argumenta:

\begin{abstract}
Isso implica que, nessa situação, nenhuma distinção clara é mantida entre escritas "original" e "traduzida", e que são os escritores principais [...] que produzem as traduções mais conspícuas ou apreciadas. Além do mais, em um estado onde novos modelos literários estão surgindo, a tradução deve se tornar um dos meios de elaboração desse novo repertório. Através de trabalhos estrangeiros, características (tanto princípios quanto elementos) são introduzidas à literatura de origem, onde não existiam. Incluem-se nelas, possivelmente, não só novos modelos de realidade para substituir os antigos e já estabelecidos que não são mais efetivos, mas uma gama inteira de outras características, como uma nova linguagem (poética), ou padrões e técnicas composicionais. ${ }^{11}$ (EVEN-ZOHAR, 1997, p. 46-47).
\end{abstract}

Cabe mencionar Eliot, que argumenta, em seu ensaio From Poe to Valéry, que tanto a teoria literária quanto a obra poética de Allan Poe alcançaram a maturidade através das traduções de Baudelaire, Mallarmé e Valéry. Nestes termos, a tradução tem um caráter peremptório quando da transmissão de influências literárias. Indo além, em um sentido mais amplo, Vladimir Macura (1990, p. 70) entende que a progressão cultural, em configurações específicas, é invariavelmente marcada por períodos em que a cultura em questão, como um todo ou em parte, exibe traços tipológicos que implicam atividades tradutórias.

Por outro lado, em que pesem todas as considerações feitas, sempre se retorna ao ponto de partida, onde a transposição criativa revela bem mais que um simples lampejo poético por parte do tradutor: na medida em que se possa depreender dela a transferência cultural, a tradução, se torna um conduto à evolução literária. E, à luz de tais asserções, ainda que se mostre plausível fazer uma análise qualitativa acerca das traduções a serem analisadas, voltase, novamente, ao ponto de partida, onde todas as linhas teóricas e correntes literárias se coadunem tal qual constituíssem uma "nova", tão logo para dar, em seguida, continuidade ao ciclo. Destarte, abstrai-se que - à parte quaisquer elementos potencialmente extrínsecos ao tema -, tudo em poesia se traduz em percepção.

11 Tradução própria de "This implies that in this situation no clear-cut distinction is maintained between 'original' and 'translated' writings, and that often it is the leading writers [...] who produce the most conspicuous or appreciated translations. Moreover, in such a state when new literary models are emerging, translation is likely to become one of the means of elaborating the new repertoire. Through the foreign works, features (both principles and elements) are introduced into the home literature which did not exist there before" (EVEN-ZOHAR, 1997, p. 46-47). 


\section{altemes \\ 10 SEMESTRE DE 2017 - N. 30}

\section{Referências}

ARROJO, Rosemary. Oficina de Tradução: a teoria na prática. São Paulo: Ática, 1986.

BASSNETT, Susan; LEFEVERE, André. Translation, History and Culture. Londres: Pinter Publishers, 1990.

BAUDELAIRE, Charles. A invenção da modernidade. Tradução de Pedro Tamen. Lisboa: Relógio D'Água Editores, 2006.

BENJAMIN, Walter. The Translator's Task. Tradução de Steven Rendall. TTR: traduction, terminologie, rédaction, v. 10, n.2, p. 151-165, 1997.

CARVALHAL, Tânia F. Tradução e recepção na prática comparatista. In: O próprio e o alheio: ensaios de literatura comparada. São Leopoldo, RS: Editora Unisinos, 2003. p. 21 7-259.

CHARAUDEAU, Patrick. L'identité culturelle entre soi et l'autre. Disponível em <www. patrick-charaudeau.com>. Acesso em: 28 jul. 2011.

CORTÁZAR, Julio. Valise de cronópio. Tradução de Davi Arriguci e João Alexandre Barbosa. São Paulo: Perspectiva, 2006.

ECO, Umberto. Quase a mesma coisa. Tradução de Eliana Aguiar. Rio de Janeiro: Record, 2007.

ELIOT, Thomas S. From Poe to Valéry. In: ELIOT, Thomas S. To Criticize the Critic. Londres: Faber and Faber, 1965. p. 15-161.

EVEN-ZOHAR, Itamar. Papers in Historical Poetics. Tel Aviv: The Porter Institute for Poetics and Semiotics, 1978.

EVEN-ZOHAR, Itamar. Polysystem studies. In: EVEN-ZOHAR, Itamar. Poetics Today. Durnham: Duke University Press, 1997.p. 9-85.

FROST, Robert. Conversations on the craft of poetry. In: FROST, Robert. Collected Poems, Prose and Plays. Nova York: The Library of America, 1995. p. 856-857.

JAKOBSON, Roman. Aspectos linguísticos da tradução. In: JAKOBSON, Roman. Linguística e comunicação. São Paulo: Cultrix, 1959.

MACURA, Vladimir. Culture and translation. In: BASSNETT, Susan; LEFEVERE, André. Translation, History and Culture. Londres: Pinter Publishers, 1990. p. 64-70.

MENDES, Oscar; AMADO, Milton. Poemas e Ensaios. São Paulo: Globo, 1999.

MINER, Earl. Poética comparada. In: MINER, Earl. Poética comparada. Tradução de Angela Gasperin. Brasília: Editora UnB, 1996. p. 27-55.

MITTMANN, Solange. Autoria e tradução: da dispersão às identificações. In: MITTMANN, Solange; GRIGOLETTO, Evandra; CAZARIN, Ercília A. (Org.). Práticas discursivas e 


\section{alemess \\ 1० SEMESTRE DE 2017 - N. 30}

identitárias: sujeito e língua. Porto Alegre: Nova Prova, 2008.

PESSOA, Fernando. The art of translating poetry. In: PESSOA, Fernando. Always Astonished: Selected Prose. Tradução de Edwin Honig. San Francisco: City Lights Books, 1988. p. 54.

POE, Edgar Allan. The rationale of verse. In: WILLIS, Nathaniel P.; LOWELL, James R.; GRISWOLD, Rufus W. (Org.). The Works of Late Edgar Allan Poe. Nova York: J. S. Redfield, 1850.

POE, Edgar Allan. The philosophy of composition. In: BAYM, Nina et al. The Norton Anthology of American Literature. Nova York: W. W. Norton \& Company, 1846-1994. p. 1534-1542.

VENUTI, Lawrence. Rethinking Translation. Londres: Routledge, 1992.

VENUTI, Lawrence. (Org.). The translation Studies Reader. Londres; Nova York: Routledge, 2000. p. 298-313.

VENUTI, Lawrence. Escândalos da tradução: por uma ética da diferença. Tradução de Laureano Pelegrin, Lucinéia Villela, Marileide Esqueda e Valéria Biondo. São Paulo: EDUSC, 2002.

VIEIRA, Else Ribeiro Pires. Por uma teoria pós-moderna da tradução. Tese (Doutorado) Programa de Pós-Graduação em Literatura Comparada. Belo Horizonte: FALE/UFMG, 1992.

ZABEL, Morton. A literatura dos Estados Unidos: suas tradições, mestres e problemas. Tradução de Célia Neves. Rio de Janeiro: Agir, 1947. 